\title{
Research and Design of Wireless Intelligent System for Ordering Management
}

\author{
Xiaoyue Wang ${ }^{1, a^{*}}$, Xinping Hong ${ }^{2, b}$, Haixu $\mathrm{Xi}^{1, \mathrm{c}}$ and Lijuan $\mathrm{Gao}^{3, \mathrm{~d}}$ \\ 1 Jiangsu University of Technology, Changzhou Jiangsu 213001, China \\ ${ }^{2}$ Wuxi Higher Vocational School of Tourism and Commerce, Wuxi Jiangsu 214046, China \\ ${ }^{3}$ Changzhou Vocational School of Industry and Trade, Changzhou Jiangsu 213012, China \\ awxy1984@jsut.edu.cn, b918964388@qq.com, ${ }^{\text {5 } 546485705 @ q q . c o m, ~}{ }^{d} 781760189 @ q q . c o m$ \\ ${ }^{*}$ The corresponding author
}

Keywords: SPCE061A; Wireless Transmission; Intelligent Management; Liquid Crystal 12864; Visual Basic

\begin{abstract}
Selecting the Single Chip Microcomputer SPCE061A as the control core, combining wireless communication technology, computer technology and other technologies, a new type of wireless intelligent system for ordering management has been designed. The system mainly includes wireless intelligent ordering terminal, data acquisition node of the total station management, the total station computer management. In the wireless intelligent ordering terminal, the corresponding content selection of dishes, soup and drinks is completed through keyboard, selected contents are displayed by liquid crystal 12864, at the same time, the corresponding contents are sent to the data acquisition node of the total station management by wireless transmission module NRF905, when the operation is abnormal, the terminal automatically sends out the alarm. The data acquisition node of the total station management receives and storages the data from the wireless transmission module NRF905, and transmits them to the total station management computer. The software control between wireless intelligent ordering terminal and the data acquisition node of the total station management is achieved by $\mathrm{C}$ language and the total station computer management is designed by the software Visual Basic. Trials show that the system not only realizes the intelligent management of catering, but also completes the paperless operation and management. Orders are transferred in real time, in this way, the phenomenon of wrong order or missing order is avoided. The wireless intelligent system for ordering management can complete autonomous ordering dishes, adding food, retreating food, checkout, calling the waiter etc, and it is easy to expand, so the wireless intelligent system for ordering management has a good application prospect.
\end{abstract}

\section{Introduction}

With the improvement of people's living standards and the changes of people's lifestyle, catering industry has a huge investment market, known as the gold industry in China. More and more catering management have reached a consensus that the traditional order management methods can not meet with the demand of the market, the traditional catering management mode is not only a waste of time, inefficient, it is but very prone to error, which will greatly reduce the quality of service, bring unnecessary losses to enterprises [1]. The wireless intelligent system for ordering management is a kind of interface order tool using wireless communication to transmit real-time data, it can meet with the actual request, it integrate with the SCM technology, communication technology, computer technology. The system solves the disadvantages of the traditional order mode, it can let customers understand the characteristics 
of food timely, and it can make customers stick out a mile to the quantity and the price of ordered food, so it is convenient for the customer's consumption, and reduces the service pressure of restaurants, so the wireless intelligent system for ordering management realizes the intelligence of catering management, reduces the cost, at the same time, the restaurant managers can also according to the specific business statistics in real time to adjust management, in order to seek more profits.

\section{Master Design of the System}

The wireless intelligent system for ordering management realizes the intelligence of catering management, and it can complete autonomous ordering dishes, adding food, retreating food, checkout, calling the waiter etc [2]. The system mainly consists of wireless intelligent ordering terminal, data acquisition node of the total station management, the total station computer management, and its structure diagram is shown in Fig. 1.

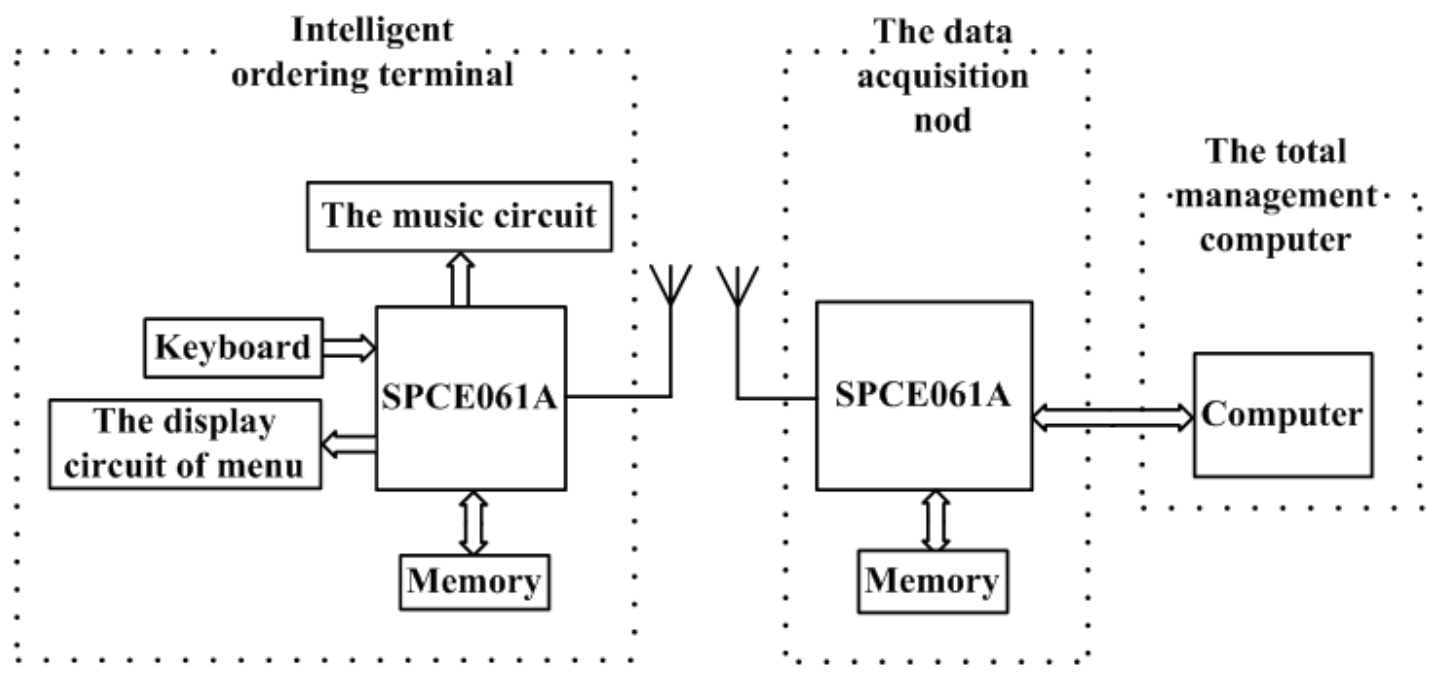

Figure 1. The structure diagram of the system

\section{Selection of the Main Modules and Demonstration of Schemes}

Power Module. The first scheme is using batteries, it is easy to change batteries at any time. The change of batteries is relatively simple, but changed batteries can cause environmental pollution easily, and the cost is high, during the use, because of the resistance, the voltage is unstable, individual cases may lead to SCM reset.

The second scheme is using AC $220 \mathrm{~V}$, it is step-downed by the $12 \mathrm{~V}$ transformer, and then it is rectified and filtered, the voltage of DC $12 \mathrm{~V}$ can be obtained, then the voltage of DC $5 \mathrm{~V}$ can be gotten through the regulator module LM7805 and the filter circuit. Finally, the voltage of DC $3.3 \mathrm{~V}$ can be gained by the regulator module LM117. At the same time, batteries are added to prevent accidental power-off, it can ensure the voltage stability in the use process, and it will not lead to SCM reset. Its use is lower, and this scheme is more conducive to environmental protection for a long term use.

Considering from the environmental protection, stable voltage, environmental protection and reliability, we choose the second scheme.

Main Control Module. The first scheme is using the SCM SPCE061A, it is the latest SCM developed by Sunplus technology, its cost is low, its performance is high, it has 32k FLASH 
ROM, it is suitable for conventional programming, high processing speed of SPCE061A can complex digital signal processing easily and quickly [3], therefore, the SCM SPCE061A has been widely used in many embedded control system.

The second Scheme is using the chip AT89C52 developed by the atmel company, it is a low voltage, high performance MCU built-in 8 bit CPU and flash storage unit, but the chip itself integrated hardware need software to achieve, the operation is complex.

Through compare and analysis, we find the SCM SPCE061A is suitable for the controlling system for ordering management. Therefore, we select the first scheme.

Transmission Mode. The first scheme is using wireless data transmission, it can avoid the unfavorable factors, and it has wide adaptability, when new equipment is added, it only need connect with the wireless transmission radio station, the wireless data transmission has good scalability, it only need to maintain the data transmission module in use.

The second Scheme is using wired data communication, its limitations is too large, not only to consider environmental factors, but also a very restrictive to the circuit layout, maintenance of wired communication link along the line need check, it is difficult to identify the fault point.

After analyzing the advantages and disadvantages of wired and wireless transmission, we choose the first scheme.

\section{Design of Main Circuits}

Power Circuit. The power circuit is shown in Fig. 2. Firstly, AC $220 \mathrm{~V}$ is step-downed by the $12 \mathrm{~V}$ transformer, and then it is rectified and filtered, the voltage of about DC $11 \mathrm{~V}$ can be obtained, then the stable voltage of DC 5V can be gotten through the regulator module LM7805 and the filter circuit, it can offer supply power to the display circuit, keyboard, the music circuit and other circuit. Finally, the stable voltage of DC $3.3 \mathrm{~V}$ can be gained by the regulator module LM1117, it provides power to the SCM SPCE061A and the wireless transmission module [4].

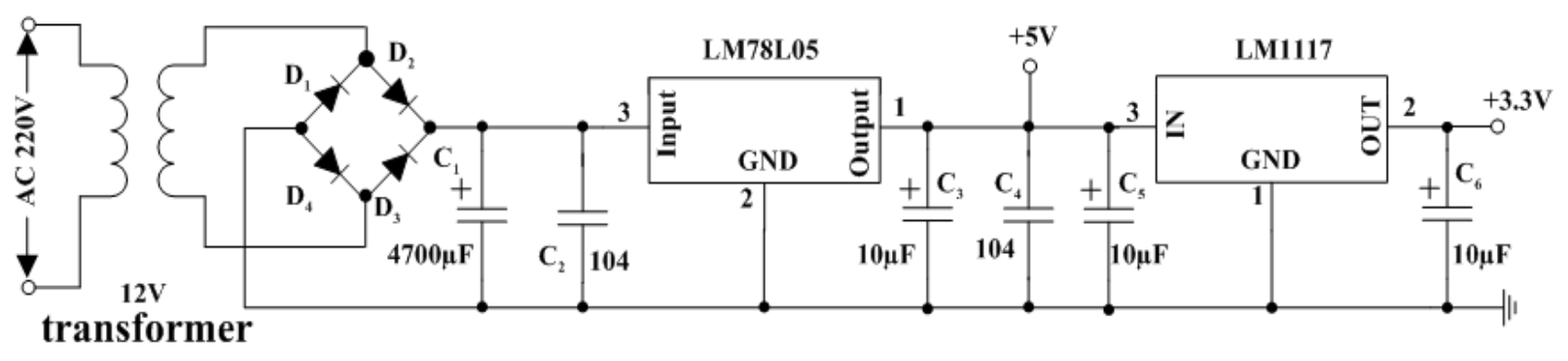

Figure 2. Power circuit

Control Circuit. Sunplus SPCE061A not only has the advantages of small size, high integration, good reliability, easy installation, stronger interrupt processing ability, but also has very strong modularity. In addition, SPCE061A is also equipped with a specialized compiler environment, providing convenience for software design. In the hardware aspect, SPCE061A has input ports and output ports, it is convenient for SPCE061A to connect with robot, computer [5]. Therefore, we all use SPCE061A as the controller in wireless intelligent ordering terminal and data acquisition node of the total station management, the connection of the controller of the wireless intelligent ordering terminal and other is shown in Fig. 3. 


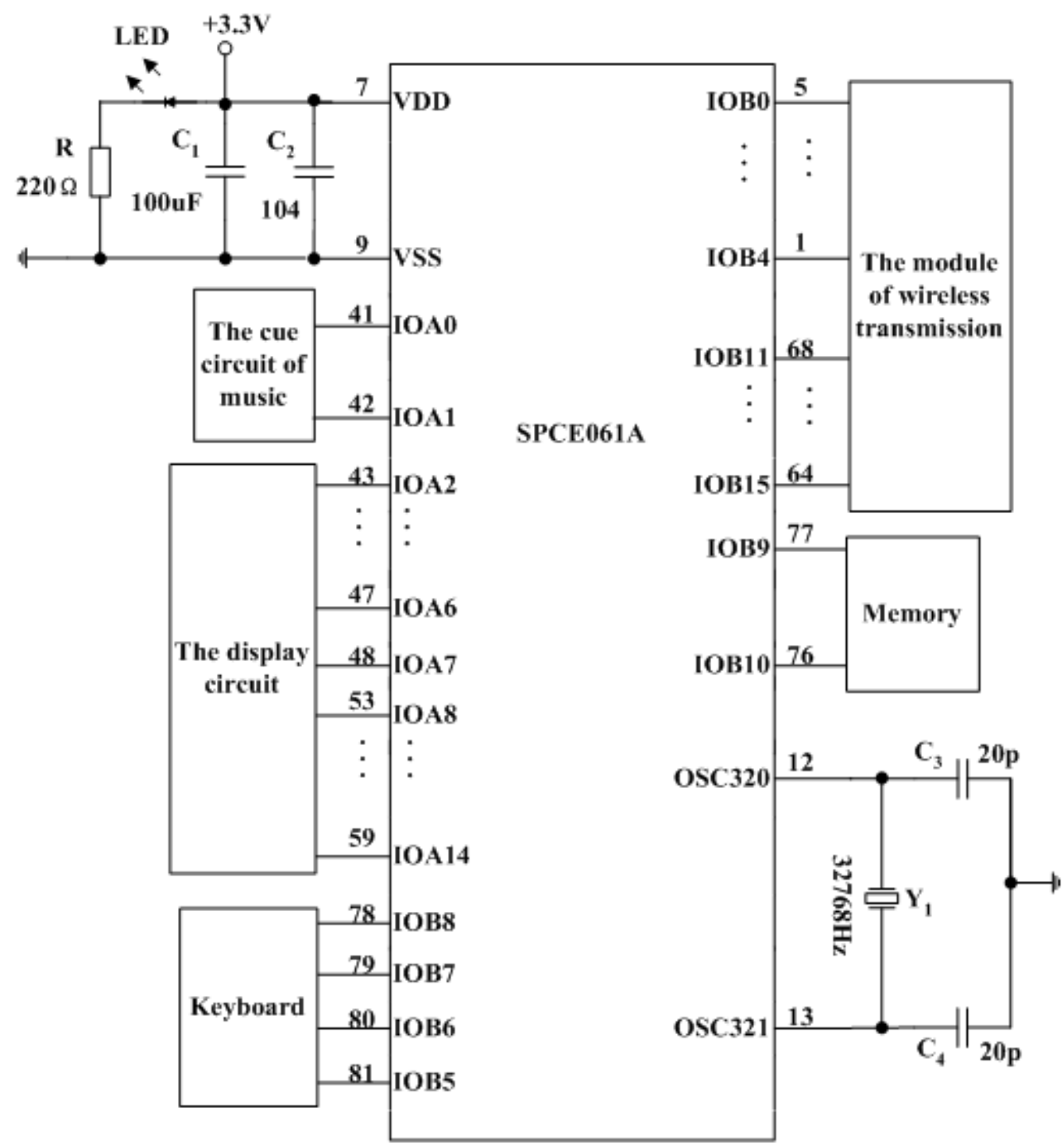

Figure 3. Control circuit of the wireless intelligent ordering terminal

Wireless Transmission Circuit. The corresponding information is transmitted by the module of wireless transmission NRF905, NRF905 is a single chip radio frequency transmitter developed by Norway Nordic Company. NRF905 is composed of frequency synthesizer, a power amplifier, demodulator, crystal oscillator, modulator and other function parts. The module of NRF905 has advantages of extremely high stability performance, relatively simple programming and good effect of partition communication, it has been widely used in intelligent system, signal acquisition, wireless sensor network and other fields [6], and the wireless transmission circuit is shown in Fig. 4. 


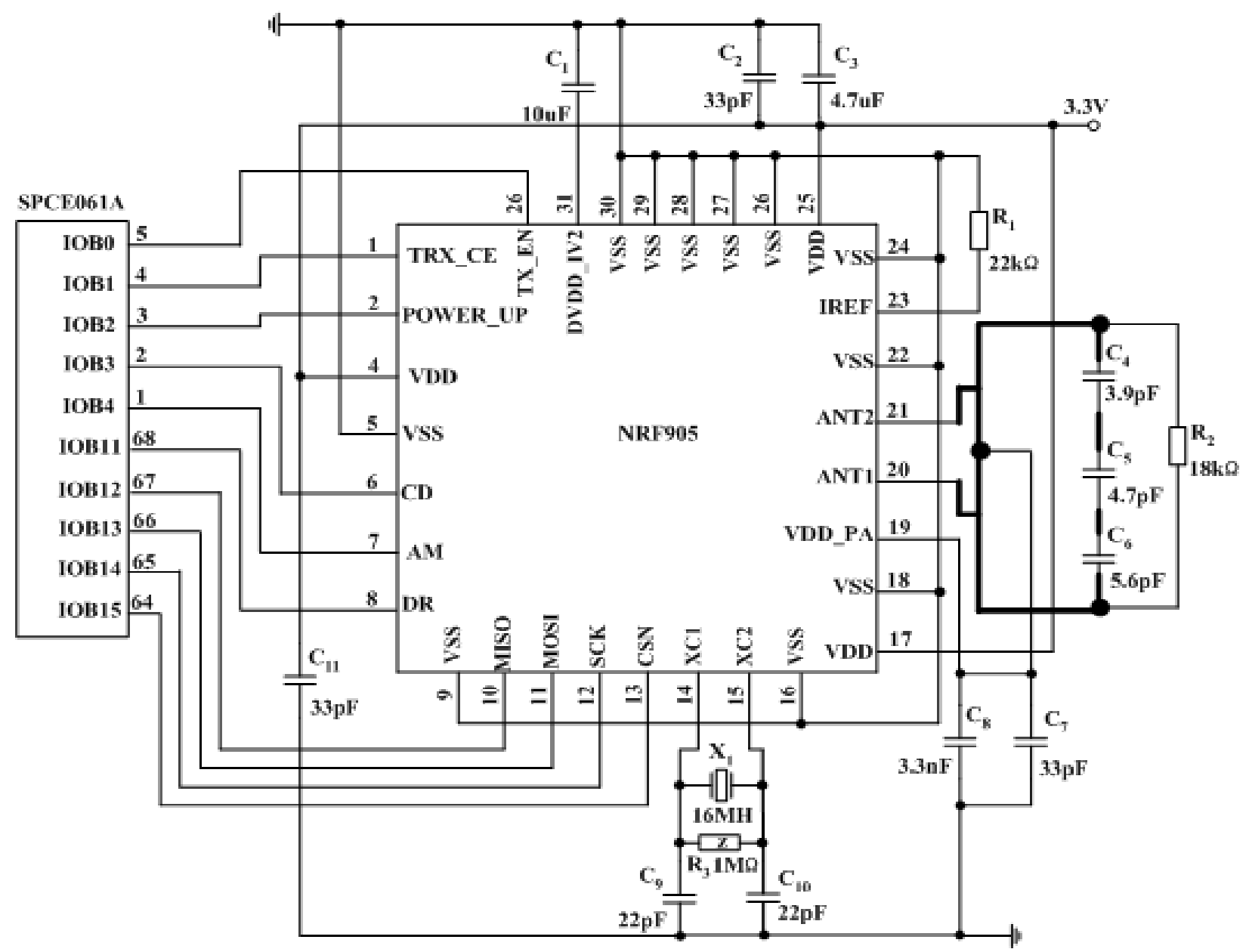

Figure 4. Wireless transmission circuit

Cue Circuit of Music. In the wireless intelligent ordering terminal, when the operation is abnormal, the SCM SPCE061A triggers interrupt, under the control of SPCE061A, the abnormal operation is stopped, and the music sound module is started [7], the corresponding circuit is shown in Fig. 5.

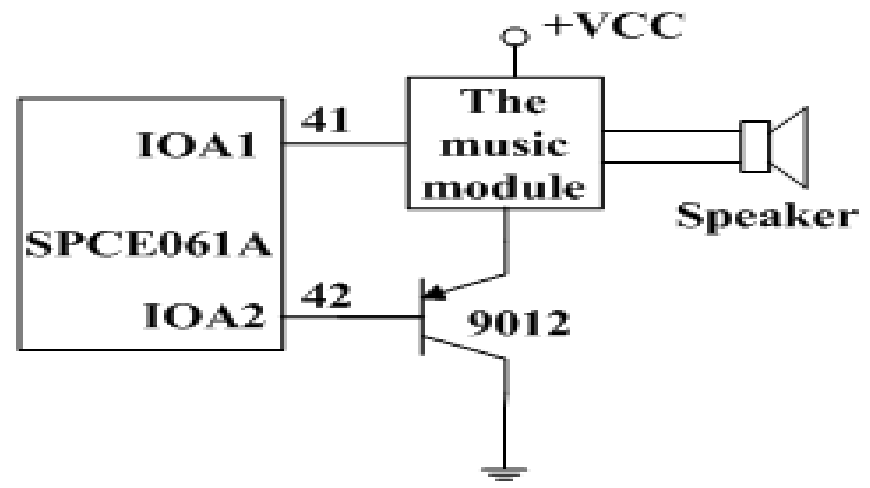

Figure 5. Cue circuit of music

Key Circuit. The $4 * 4$ matrix keyboard circuit is shown in Fig. 6, the key circuit uses only four IO interfaces, it can complete functions which the general circuit needs eight IO interfaces to complete. The 16 push-buttons are defined as 1, 2, 3, 4, 5, 6, 7, 8, 9, 0, A, B, C, D, E, and F. 
The number push-buttons are used for table numbers, serial and amounts of dishes, A is choosing dishes, $\mathrm{B}$ is ending ordering, $\mathrm{C}$ is transmission, $\mathrm{D}$ is menu list, $\mathrm{F}$ is $\mathrm{OK}$.

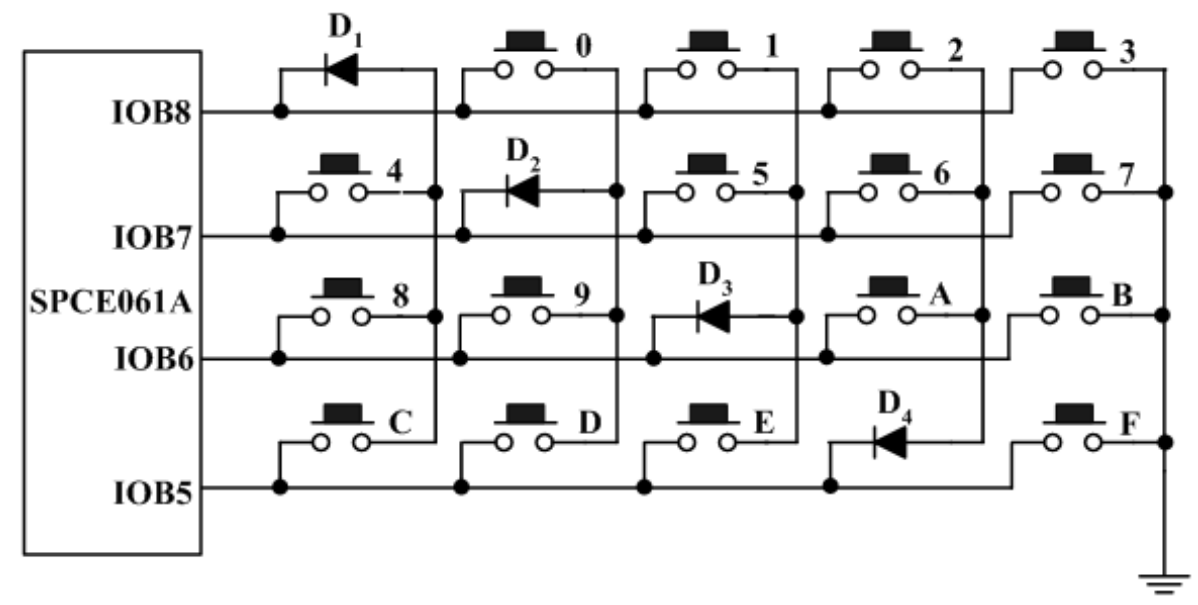

Figure 6. Key circuit

\section{Software Design of the System}

Software of the wireless intelligent system for ordering management is programmed by $\mathrm{C}$ language and Visual Basic, has completed the control function of the system, in this way, the control function of the system is completed [8][9][10]. The flow chart of the main program of the wireless intelligent ordering terminal, the flow chart of the wireless transmission and the flow chart of ordering management in total station are shown in Fig. 7, Fig. 8 and Fig. 9 respectively.

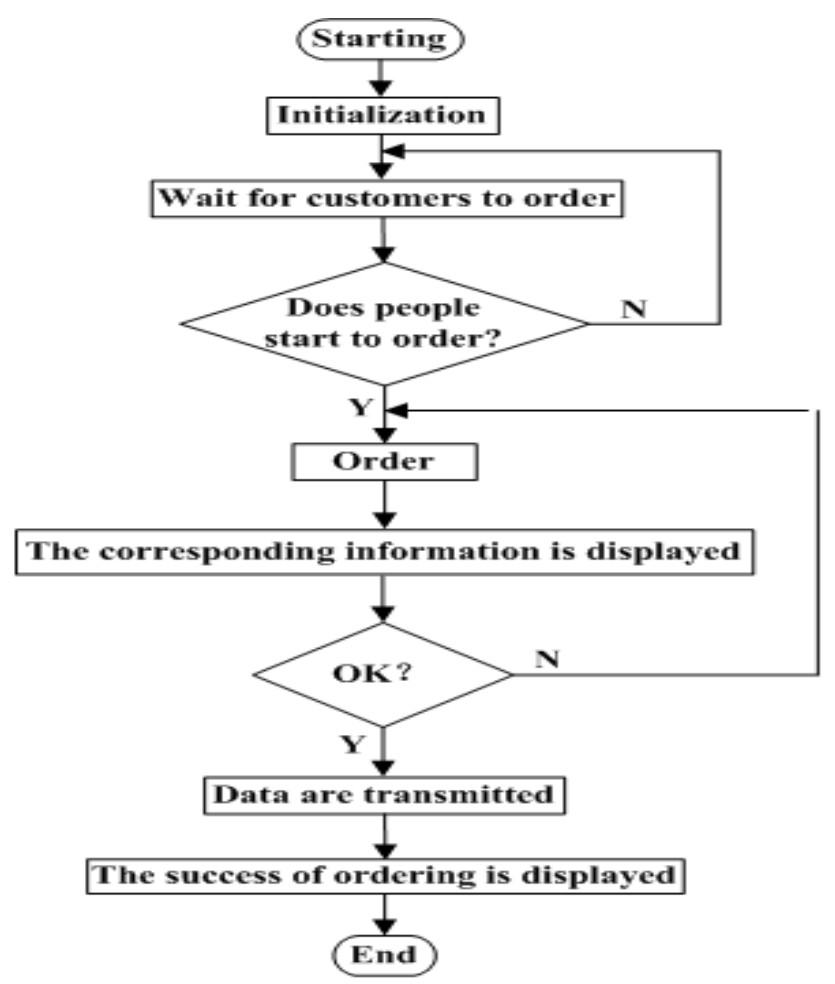

Figure 7. Flow chart of the main program of the wireless intelligent ordering terminal 


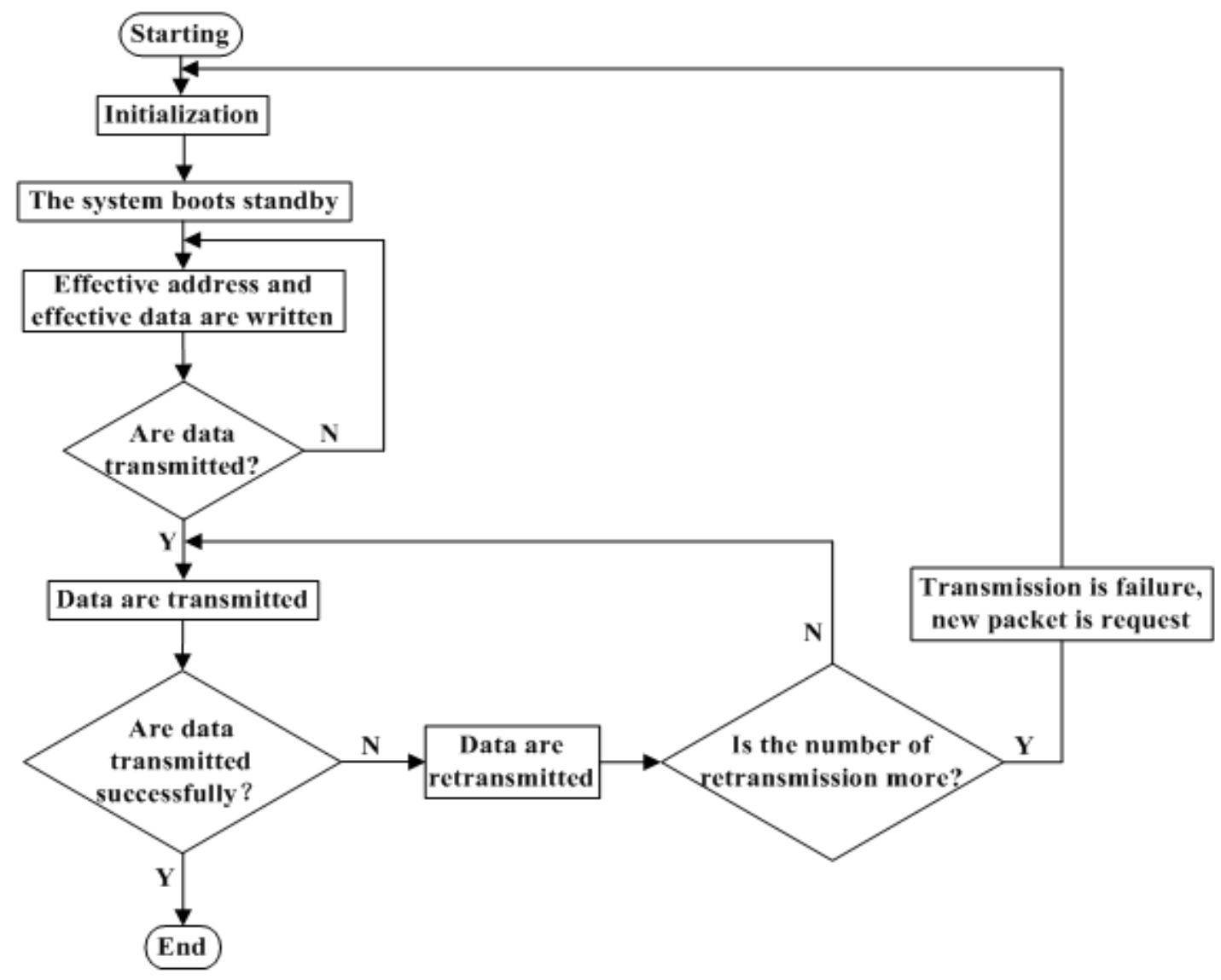

Figure 8. Flow chart of the wireless transmission

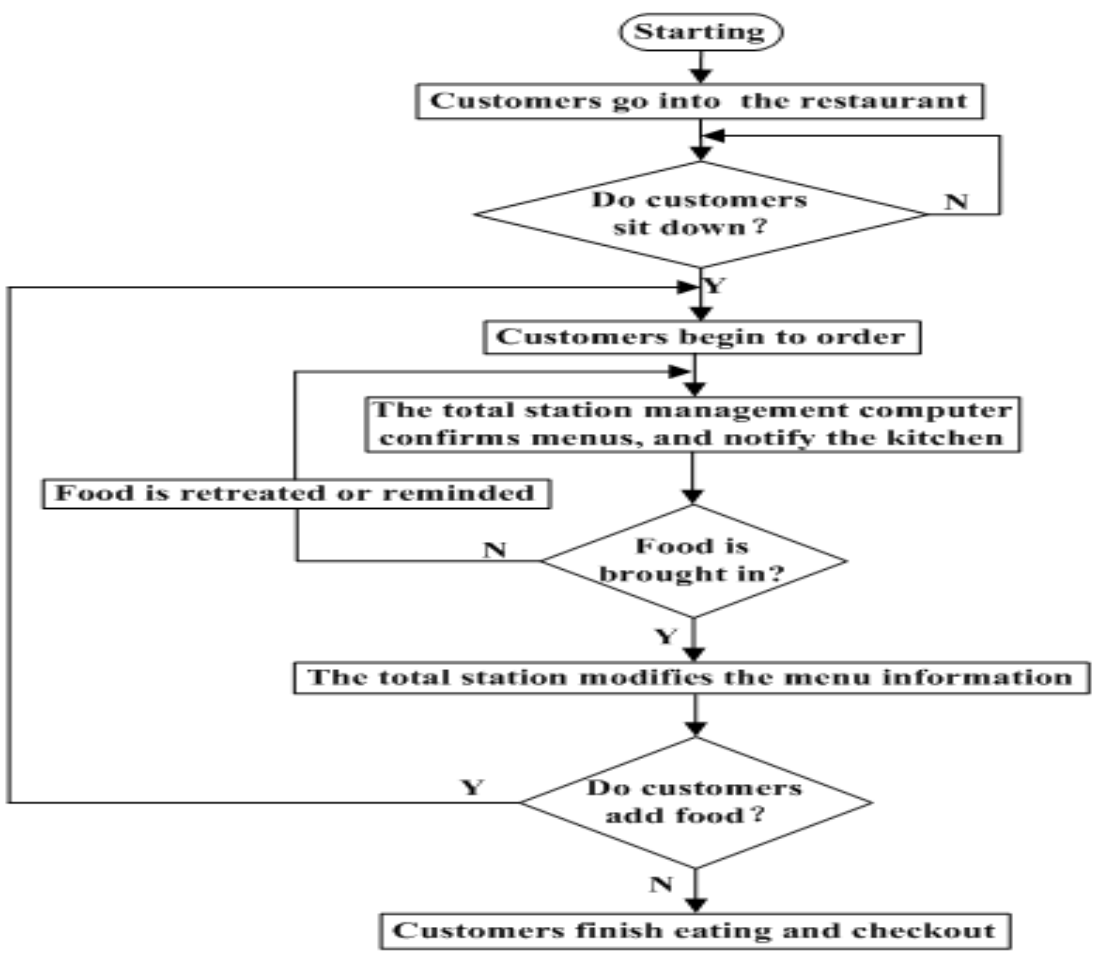

Figure 9. Flow chart of ordering management in total station 
The System Testing. The wireless intelligent system for ordering management has been developed and experienced, it has been on trial in the open laboratory of the department of physics and electronic engineering. Operation results show that the operation is easy, data transmission is accurate, working is stable, the can well realize the intelligent management of order. Terminal ordering interface, main interface of the total station computer management, and bill management interface are shown in Fig. 10, Fig. 11 and Fig. 12 respectively.

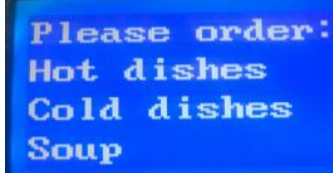

Figure 10. Terminal ordering interface

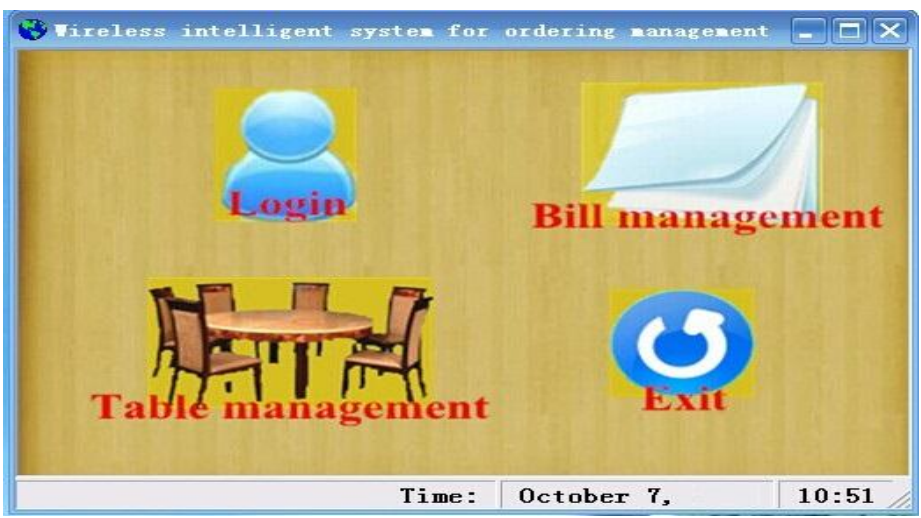

Figure 11. Main interface of the total station computer management

\begin{tabular}{|c|c|c|c|}
\hline Time $=\mathrm{O}$ & ctober 9 , & Table number : & 07 \\
\hline \multicolumn{4}{|c|}{ Consumption list } \\
\hline No. & Name of dishes & Unit price (yuan) & Number \\
\hline 1 & Fireed potato silk & 6 & 1 \\
\hline 2 & Spareribs & 22 & 1 \\
\hline 3 & Shredded meat in chilli sauce & 16 & 1 \\
\hline 4 & Braised eggplant & 10 & 1 \\
\hline 5 & Steamed perch & 36 & 1 \\
\hline 6 & Eggdrop soup & 5 & 1 \\
\hline \multicolumn{4}{|l|}{ Total (yuan) } \\
\hline & Print & Exit & \\
\hline
\end{tabular}

Figure 12. Bill management interface

\section{Conclusion}

Starting from the current development situation of catering management and practical application, comprehensively utilizing a variety of technology, a set of the wireless intelligent 
system for ordering management has been researched and designed. The system achieves a good wireless intelligent management function for catering, it is convenient for the customer's consumption, and saves a lot of manpower, material and financial resources for restaurants. The design will have a positive role in enhancing service quality and reducing the cost in restaurants, the wireless intelligent system for ordering management has the advantages of high intelligence, high ratio of performance to price, stable performance, convenient use and easy installation. So it has a good application prospect and will play an immeasurable role in promoting the establishment of a harmonious society.

\section{Acknowledgements}

The work was supported by the natural science foundation of youth project of Jiangsu University of Technology under Grant KYY14018 and higher education research project of Jiangsu University of Technology under Grant KYY15504 and social science foundation of youth project of Jiangsu University of Technology under Grant KYY14534 and modern educational technology research 2015 annual project of Jiangsu Province of China under Grant 2015-R-45347.

\section{References}

[1] X.I. Fei and M.L. Jia: Design and Implemetation of Online Customs Agent Management System Based on Workflow, Computer and Modernization, Vol.29 (2013) No.8, p.214, (In Chinese).

[2] .M. Yang: Chinese Traditional Culture and Modern Packaging Design of Industrial Products, China Packaging Industry, Vol. 8 (2014) No.4, p.55, (In Chinese).

[3] W.G. Ran, X. Jing and Q. Liu: Computer System in the Application of Automation Instruments and Meters, Automation \& Instrumentation, Vol.34 (2014) No.2, p.117, (In Chinese).

[4] S.B. Tong and C.Y. Hua: Basis of Analogue Electronic Technique (Higher Education Press, China 2012), (In Chinese).

[5] S.F. Qiu: Principle and Application of Sunplus Sixteen Bit Single-chip Microcomputer, (Xi'an Electronic and Science University Press, China 2011), (In Chinese).

[6] K.J. Negus, A. P. Stephens and J. Lansford: IEEE Personal Communications, Vol.7 (2000) No.1, p.55.

[7] Y.H. Lu: The Electronic System Design Tutorial (National Defence Industry Press, China 2005), (In Chinese).

[8] R.X. NI: Hardware Developing of Equipment Status Monitoring Device Based on Embedded Computing Technology, Computer Technology and Development, Vol.19 (2009) No.12, p. 220, (In Chinese).

[9] W. Luo: Application of Single-chip Microcomputer (People's Posts and Telecommunications Press, China 2010), (In Chinese).

[10] H.B. Wang: Visual Basic Program Design (China Mechine Press, China 2008), (In Chinese). 


\section{Authors' Information}

Jiangsu University of Technology

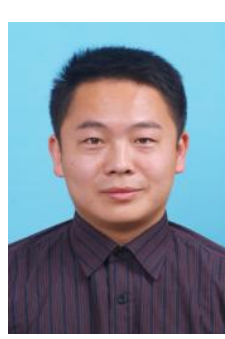

Xiaoyue Wang, male, born in 1984, Changzhou, Jiangsu. He received the master's degree in Computer Technology from Jiangsu University of Science and Technology. He used to be a lecturer at the Institute of Computer Engineering in Jiangsu University of Technology. Currently, he is a teaching management staff in Dean's Office. His interests are in education management, cultivation of talents, talent evaluation, digital teaching resource development and computer technology.

Wuxi Higher Vocational School of Tourism and Commerce

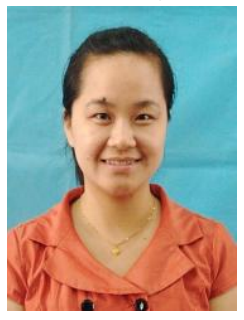

Xinping Hong, female, born in 1977, Wuxi, Jiangsu. She received the bachelor's degree in English Education from Suzhou University and the master's degree from Shanghai Normal University. Now, she is an associate professor in Wuxi Higher Vocational School of Tourism and Commerce. Her interest is in English education and tourism translation. In addition, she has certificates of English tour guide and tour leader, and possesses practical experience in tourism.

Jiangsu University of Technology

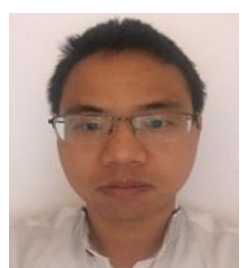

Haixu Xi, male, born in 1981, Jishui, Jiangxi. He received the master's degree in Educational Technology from Nanjing Normal University. Currently, he is a lecturer at the Institute of Computer Engineering in Jiangsu University of Technology. His interests are in cultivation of talents, digital teaching resource development and multimedia technology.

Changzhou Vocational School of Industry and Trade

Lijuan Gao, female, born in 1988, Liyang, Jiangsu. She received the master's

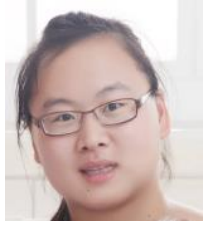
degree in the Internet of Things Engineering College from Jiangnan University. Currently, she is an assistant lecturer in Changzhou Vocational School of Industry and Trade. Her interests are in digital teaching resource development, network technology and multimedia technology. 